
Д.В. Погонцева

\title{
ВИДЫ ДИСКРИМИНАЦИИ ПО ВНЕШНЕМУ ОБЛИКУ
}

\begin{abstract}
Аннотация. В статье рассматривается феномен дискриминации по внешнему облику. Приводятся теоретические и экспериментальные работы зарубежных исследователей, посвященные такому виду дискриминации, как лукизм. Лукизм - термин, который используется в западной литературе и описывает феномен дискриминации красивых людей. При этом в большинстве работ отмечается проявление данного феномена, в форме «позитивной дискриминации». Проанализированные зарубежные исследования дискриминации в различных ситуациях взаимодействия указывают на то, ито красивым людям устанавливается более высокая заработная плата, выме оценки у студентов и т.д. Приводятся данные анализа эмпирического исследования дискриминационного отношения к людям с красивым внешним обликом. В представлении респондентов, в России существует дискриминация по внешнему облику (около 89\%), и она представлена как лукизмом (дискриминация красивых), так и дискриминачионным отночением к слишком полным/худым людям и людям с ростом значимо больще или меньше среднего.
\end{abstract}

Ключевые слова: дискриминация, лукизм, привлекательный внешний облик, красота, категоризация, отночение, выгода, стереотип, взаимодействие, внешний облик.

T工

а современном этапе можно отметить рост количества исследований, посвященных роли влияния внешнего облика на поведение людей в различных сферах жизни (реклама, судебные решения, трудоустройство, выборы и т.д.), а также феноменам категоризации и дискриминации другого по внешнему облику. В работах, посвященных дискриминации, отмечается, что причина дискриминации может быть основана как на устойчивых характеристиках внешнего облика человека (пол, этническая принадлежность, рост, возраст), так и среднеустойчивых параметрах (вес). В свою очередь, мы можем отметить, что привлекательный внешний облик - это совокупность индивидо-конституциональных характеристик, которые считаются приближенными к «идеалу красоты» стереотипу, существующему в определенном обществе, в исторически ограниченный период. Но привлекательный внешний облик, который является синонимом «красоты», в свою очередь может являться причиной дискриминации. Так, W. Safire ${ }^{1}$ отмечает, что сам термин «лукизм» был впервые использован в печатном издании в 1978 г. в Washington Post Magazine в статье, посвященной полным людям, которые «испытывают на себе дискриминацию, основанную на внешнем облике». Позже, как отмечает W. Safire, в 1999 г. понятие «лукизм» было дано Оксфордским словарем.

1 Safire W. The right word in the right place at the right time: wit and wisdom from the popular "On language" column in The New York times magazine // Simon and Schuster. 2004. P. 189.
John Strang, Gerry Vivian Stimson понимают под лукизмом - культурный аспект категоризации себя и другого как красивых/не красивых. Это является основным фактором для выбора характера отношений. Авторы также поднимают вопрос о «нарциссическом лукизме» - как завышенной самооценке собственной красоты ${ }^{2}$.

C. Costin говорит о лукизме как о современной жизненной философии, когда «не важно, что ты из себя представляешь, а важно только то, как ты выглядишь»³. В философии лукизма автор видит основную проблему юношеского недовольства своей внешность и подростковой анорексии - стремление молодых девушек похудеть. В свою очередь M.M. Sprague, K.K. Keeling говорят о том, что проблема лукизма затрагивает не только девочек, но и мальчиков, более того, по мнению автора, все чаще мальчики и юноши становятся объектом дискриминации, т.е. лукизма ${ }^{4}$. S. Giordano отмечает, что, говоря о стремлении улучшить свое тело, которое часто приводит к расстройству питания, наряду с лукизмом, необходимо

\footnotetext{
2 Strang J., Stimson G.V. AIDS and drug misuse: the challenge for policy and practice in the 1990s // Taylor \& Francis. 1990. P. 166.

3 Costin C. Your dieting daughter: is she dying for attention? // Psychology Press. 1996. P. 240.

4 Sprague M.M., Keeling K.K. Discovering their voices: engaging adolescent girls with young adult literature // International Reading Assoc. 2007. P. 24.
} 


\section{Сценарий вашего успеха}

также рассматривать и такое явление как «healthism» ${ }^{5}$, которое автор интерпретирует как дискриминацию людей выглядящих здоровыми или не здоровыми.

По мнению V.F. Shaw, большинство людей не принимают «лукизм» всерьез, чаще связывая его с сексизмом в целом, поскольку в большинстве случаев эмпирические исследования говорят о дискриминации красивых и некрасивых женщин, в то время как мужчины редко становятся объектом эмпирических исследований ${ }^{6}$. L.A. Grunig, L.C. Hon, E.L. Toth рассматривают лукизм как одну из форм сексуальных домогательств на работе, мотивируя это высказыванием, что «другой обращает внимание больше на внешность, чем на выполняемую работу» ${ }^{7}$. L. Patzer Gordon ${ }^{8}$ отмечает, что в последнее время внешний вид и особенно красота собеседника в наибольшей степени влияет на взаимоотношения с ним. Автор также говорит о том, что на эволюционном уровне дискриминация некрасивых на «брачном рынке» может быть оправдана, однако более красивые люди получают гораздо больше преимуществ в повседневной жизни: на приеме у врача, при получении скидок в магазине, при обслуживании в ресторане и т.д.

Исходя из этих работ, мы видим, что основной принцип лукизма: «что красиво - то хорошо», т.е. проявляется позитивная дискриминация. На основании данного положения можно выделить ряд работ, в которых данное утверждение подкрепляется эмпирическими данными. Как отмечают I.R. Olson, Ch. Marshuetz ${ }^{9}$, красивые люди всегда получают больше льгот: от более высокой социальной оценки до более высокой зарплаты. Проводя теоретический анализ данной проблемы, авторы отмечают, что практически все работы, изучающие аттрактивность внешнего облика, так или иначе затрагивают данный вопрос и отмечают, что такой стереотип существует и зачастую он оказывает влияние на все другие оценки. В другом исследовании авторы рассматривали проблему «красивое значит хорошее, или хорошее значит красивое» на примере оценок школьников ${ }^{10}$. Они изучали взаимосвязь оценок

\footnotetext{
5 Giordano S. Exercise and Eating Disorders: An Ethical and Legal Analysis. Taylor \& Francis, 2009. P. 26.

6 Shaw V. F. Coping with Sexual Harassment and Gender Bias. The Rosen Publishing Group, 2000. P. 106.

7 Grunig L.A., Hon L.C., Toth E.L. Women in Public Relations: How Gender Influences Practice. Routledge, 2004. P. 440.

8 Patzer G.L. Looks: why they matter more than you ever imagined // AMACOM Div American Mgmt Assn. 2008. P. 282.

9 Olson I.R., Marshuetz Ch. Facial Attractiveness Is Appraised in a Glance // Emotion. Vol. 5. Is. 4. December 2005. P. 498-502.

10 Hamermesh D., Parker A. Beauty in the classroom: instructors' pulchritude and putative pedagogical productivity // Economics of Education Review. Vol. 24. Is. 4. August 2005. P. 369-376.
}

внешней аттрактивности и способностей (академических и физических) в ходе проведения социометрии. В своем исследовании они просили школьников назвать трех самых красивых учеников, самых умных и самых успешных в спорте. В итоге они показали, что детей более умных и спортивно-развитых их одноклассники считают более красивыми.

D. Hamermesh ${ }^{11}$ выявил закономерность успеха на выборах и внешней красотой кандидатов. В своей работе автор рассмотрел 312 кандидатов различных политических выборов в период за 1966-2004. Это исследование показало, что не существует дискриминация в отношении плохо выглядящего человека. Однако красивые люди имеют более высокий показатель по результатам голосования. Подобное исследование также проводили N. Berggren, H. Jordahl, P. Poutvaara $^{12}$, которые изучили отношение респондентов к 1929 участникам различных политических выборов Финляндии, по данным авторам - оценка внешнего облика как привлекательного повышает успех на выборах на $20 \%$.

В другой работе D. Hamermesh, A. Parker исследовали взаимосвязь внешности студентов и их оценок, ими было выявлено, что студенты, которых преподаватели считают обладающими более аттрактивным внешним обликом, получают более высокие учебные оценки ${ }^{13}$. Эта закономерность больше присуща для мужчин, чем для женщин-преподавателей. Авторы так же подчеркивают, что оценка в ряде случаев зависела не от уровня знаний, а занижалась или завышалась (в среднем на 0,5-1 балл) в зависимости от внешнего облика студента и отношения к нему преподавателя. Со своей стороны студенты не замечали данную тенденцию, отмечая, что все оценки ставятся заслуженно. На втором этапе, на котором опрашивали студентов, было выявлено, что такое мнение о справедливости оценок, объяснялось тем, что студенты также склонны считать, что красивые люди умнее, и поэтому заслуживают более высоких оценок. Таким образом, Д. Хамермеш и Э. Паркер делают вывод о влиянии стереотипа «что красиво - то хорошо» на повседневную жизнь.

Кроме исследований лукизма, можно выделить работы, посвященные двум другим видам дискриминации,

11 Hamermesh D.S. Changing looks and changing "discrimination": The beauty of economists Economics Letters. Vol. 93, Issue 3, December 2006. P. 405-412.

12 Berggren N., Jordahl H., Poutvaara P. The looks of a winner: Beauty and electoral success // Journal of Public Economics. Vol. 94. Is. 1-2. Feb. 2010. P. 8-15.

13 Hamermesh D., Parker A. Beauty in the classroom: instructors' pulchritude and putative pedagogical productivity // Economics of Education Review. Vol. 24. Is. 4. August 2005. P. 369-376. 


\section{Психология и психотехника 9(60) • 2013}

основанной на оценке внешнего облика: weightism дискриминация людей с очень большим и/или малым весом и highism - дискриминация по росту. Так, как отмечает группа ученых из $\mathrm{CШA}^{14}$, дискриминация по весу и росту распространена в американском обществе и по количеству зафиксированных случаев приближается к показателям расовой дискриминации, особенно среди женщин. При этом дискриминация по весу и росту имеет место как в сфере занятости (при трудоустройстве), так и в межличностных отношениях (обидные прозвища, шутки, сарказм).

Таким образом, мы можем заключить, что проблема оценки и категоризации другого по внешнему облику может основываться на разных аспектах внешнего облика (рост, вес, физическая привлекательность), однако все виды дискриминаций по внешнему облику являются предметом изучения в зарубежных исследованиях (в основном в США и Европе) и практически не затрагиваются в российских исследованиях. Исходя из этого, мы поставили цель пилотажного исследования: изучить, существует ли данный феномен в России.

Нами было проведено пилотажное исследование, в рамках которого мы опросили 100 человек (60 женщин, 40 мужчин) в возрасте от 18 до 30 лет, которым был предложен ряд вопросов, направленных на выявление случаев дискриминации по внешнему облику из личного опыта респондентов. Исходя из анализа зарубежных работ, нами были выделены три параметра внешнего облика: рост, вес, физическая привлекательность.

Описывая опыт дискриминационного отношения на основе роста человека, только $9 \%$ указали, что неоднократно сталкивались с данным видом дискриминации на уровне шуток, прозвищ и т.д., 14\% сталкивались единожды, а около $77 \%$, что не сталкивались с таким типом отношений в личном опыте.

Отвечая на вопрос дискриминации на основе веса человека, 55\% отметили, что не сталкивались с таким типом дискриминации, $25 \%$ - сталкивались однажды, и около $20 \%$ указали, что часто сталкиваются с таким типом отношения.
25\% респондентов отметили, что испытывали дискриминационное отношение других по поводу их внешнего облика, на уровне шуток, обидных прозвищ неоднократно, $31 \%$ - что такое в их жизни случалось «однажды» и 44\% - указали, что не сталкивались с дискриминационным отношением, основанном на оценке привлекательности внешнего облика.

Говоря о половых различиях опыта дискриминации по внешнему облику, можно отметить, что только в описаниях дискриминационного отношения на основе веса обнаружены значимые различия, поскольку девушки значимо чаще отмечали, что испытывают данный вид дискриминационного отношения.

Далее, мы опросили респондентов, считают ли они, что в российской действительности существуют различные виды дискриминации по внешнему облику. Около $31 \%$ указали, что существует дискриминация людей очень маленького и очень большого роста, 74\% отметили дискриминацию очень полных и очень худых людей и чуть более $90 \%$ сообщили, что присутствует дискриминация непривлекательных людей.

Таким образом, можно отметить, что наблюдения респондентов указывают на то, что дискриминационное отношение, основанное на оценки внешнего облика, в том числе на оценке человека как привлекательного/непривлекательного, существует в российской действительности. При этом теоретический анализ указывает на не разработанность этой проблемы в российской психологии.

Как отмечает В.А. Лабунская ${ }^{15}$, «внешний облик становится одним из важнейших средств построения типологий, выделения и распознания определенных социальных групп, страт, описания стилей жизни. ... Внешний облик человека становится способом визуальной коммуникации и стратификации». Таким образом, внешний облик становится одним из факторов для дискриминации, при этом она может быть основана на различных категориях: вес, рост, физическая привлекательность, а также пол, этническая принадлежность и т.д. Данный феномен является актуальным, однако на данный момент малоизученным.

\section{Сиисок литературь:}

1. Воробьев С.М. Конституционно-правовые основы борьбы с дискриминацией в России // LEX RUSSICA (PУCСКИЙ ЗАКОН). 2013. № 1. С. 16-24.

2. Лабунская В.А. «Видимый человек» как социально-психологический феномен // Социальная психология и общество. 2010. № 1. С. 26-39.

14 Puhl R.M., Andreyeva T., Brownell K.D. Perceptions of weight discrimination: prevalence and comparison to race and gender discrimination in America // International Journal of Obesity. 2008. № 32. P. 992-1000.
15 Лабунская В.А. «Видимый человек» как социально-психологический феномен // Социальная психология и общество. 2010. № 1. С. 26-39. 


\section{Сценарий вашего успеха}

3. Berggren N., Jordahl H., Poutvaara P. The looks of a winner: Beauty and electoral success // Journal of Public Economics. Vol. 94. Is. 1-2. Feb. 2010. P. 8-15.

4. Costin C. Your dieting daughter: is she dying for attention? // Psychology Press. 1996. P. 240.

5. Giordano S. Exercise and Eating Disorders: An Ethical and Legal Analysis. Taylor \& Francis, 2009.

6. Grunig L.A., Hon L.C., Toth E.L. Women in Public Relations: How Gender Influences Practice. Routledge, 2004.

7. Hamermesh D.S. Changing looks and changing "discrimination": The beauty of economists Economics Letters. Volume 93. Issue 3. December 2006. P. 405-412.

8. Hamermesh D., Parker A. Beauty in the classroom: instructors' pulchritude and putative pedagogical productivity // Economics of Education Review. Vol. 24. Is. 4. August 2005. P. 369-376.

9. Olson I.R., Marshuetz Ch. Facial Attractiveness Is Appraised in a Glance // Emotion. Vol. 5. Is. 4. December 2005. P. 498-502.

10. Patzer G.L. Looks: why they matter more than you ever imagined. AMACOM Div American Mgmt Assn, 2008.

11. Puhl R.M., Andreyeva T., Brownell K.D. Perceptions of weight discrimination: prevalence and comparison to race and gender discrimination in America // International Journal of Obesity. 2008. № 32. P. 992-1000.

12. Safire $W$. The right word in the right place at the right time: wit and wisdom from the popular «On language» column in The New York times magazine. Simon and Schuster, 2004.

13. Shaw V.F. Coping with Sexual Harassment and Gender Bias. The Rosen Publishing Group, 2000.

14. Sprague M.M., Keeling K.K. Discovering their voices: engaging adolescent girls with young adult literature. International Reading Assoc., 2007.

15. Strang J., Stimson G.V. AIDS and drug misuse: the challenge for policy and practice in the 1990s. Taylor \& Francis, 1990.

\section{References (transliteration):}

1. Vorobev S.M. Konstitucionno-pravovye osnovy bor'by s diskriminaciey v Rossii // LEX RUSSICA (RUSSKIY ZAKON). 2013. № 1. C. 16-24.

2. Labunskaya V.A. «Vidimyy chelovek» kak social'no-psihologicheskiy fenomen // Social'naya psihologiya i obschestvo. 2010. № 1. S. 26-39.

3. Berggren N., Jordahl H., Poutvaara P. The looks of a winner: Beauty and electoral success // Journal of Public Economics. Vol. 94. Is. 1-2. Feb. 2010. P. 8-15.

4. Costin C. Your dieting daughter: is she dying for attention? // Psychology Press. 1996. P. 240.

5. Giordano S. Exercise and Eating Disorders: An Ethical and Legal Analysis. Taylor \& Francis, 2009.

6. Grunig L.A., Hon L.C., Toth E.L. Women in Public Relations: How Gender Influences Practice. Routledge, 2004.

7. Hamermesh D.S. Changing looks and changing "discrimination": The beauty of economists Economics Letters. Volume 93. Issue 3. December 2006. P. 405-412.

8. Hamermesh D., Parker A. Beauty in the classroom: instructors' pulchritude and putative pedagogical productivity // Economics of Education Review. Vol. 24. Is. 4. August 2005. P. 369-376.

9. Olson I.R., Marshuetz Ch. Facial Attractiveness Is Appraised in a Glance // Emotion. Vol. 5. Is. 4. December 2005. P. 498-502.

10. Patzer G.L. Looks: why they matter more than you ever imagined. AMACOM Div American Mgmt Assn, 2008.

11. Puhl R.M., Andreyeva T., Brownell K.D. Perceptions of weight discrimination: prevalence and comparison to race and gender discrimination in America // International Journal of Obesity. 2008. № 32. P. 992-1000.

12. Safire $\mathrm{W}$. The right word in the right place at the right time: wit and wisdom from the popular «On language» column in The New York times magazine. Simon and Schuster, 2004.

13. Shaw V.F. Coping with Sexual Harassment and Gender Bias. The Rosen Publishing Group, 2000.

14. Sprague M.M., Keeling K.K. Discovering their voices: engaging adolescent girls with young adult literature. International Reading Assoc., 2007.

15. Strang J., Stimson G.V. AIDS and drug misuse: the challenge for policy and practice in the 1990s. Taylor \& Francis, 1990. 